\title{
New eSSR and gSSR markers added to Australian barley maps
}

\author{
Kerrie L. Willsmore ${ }^{\mathrm{A}}$, Paul Eckermann ${ }^{\mathrm{B}}$, Rajeev K. Varshney ${ }^{\mathrm{E}}$, Andreas Graner ${ }^{\mathrm{C}}$, \\ Peter Langridge ${ }^{\mathrm{D}}$, Margaret Pallotta ${ }^{\mathrm{D}}$, Judy Cheong ${ }^{\mathrm{A}}$, and Kevin J. Williams ${ }^{\mathrm{A}, \mathrm{F}}$ \\ ${ }^{A}$ Molecular Plant Breeding CRC, South Australian Research \& Development Institute, \\ GPO Box 397, Adelaide, SA 5001, Australia. \\ ${ }^{B}$ University of Adelaide, PMB 1, Glen Osmond, SA 5064, Australia. \\ ${ }^{\mathrm{C}}$ International Crops Research Institute for the Semi-Arid Tropics (ICRISAT), Patancheru, AP - 502 324, India. \\ DInstitute of Plant Genetics and Crop Plant Research (IPK), Corrensstrasse 3, D-06466 Gatersleben, Germany. \\ ${ }^{E}$ Australian Centre for Plant Functional Genomics, PMB 1, Glen Osmond, SA 5064, Australia. \\ ${ }^{\mathrm{F} C}$ Corresponding author. Email: williams.kevin@saugov.sa.gov.au
}

\begin{abstract}
To enhance genetic maps of barley previously developed in Australia for identifying markers useable in molecular breeding, a new set of simple sequence repeat (SSR) and indel markers was added to the maps. These markers were developed through (i) database mining of barley expressed sequence tag (EST) sequences, (ii) comparative barley-rice genome analysis, and (iii) screening of a genomic library with SSR probes. The primer set selected for this study comprised 216 EST-SSR (eSSR) and 25 genomic SSR (gSSR) markers, which were screened for polymorphism on 4 doubled haploid (DH) or recombinant inbred line (RIL) populations. In total, 81 new markers were added to the maps, with good coverage on all 7 chromosomes, except $6 \mathrm{H}$, which only had 2 new markers added. The marker order of previously published maps was re-evaluated by comparing recombination fractions calculated by 2 methods to discover the best position for each marker. The new SSR markers were then added to the updated maps. Several of these new markers are linked to important barley disease resistance genes such as those for cereal cyst nematode, spot form of net blotch, and leaf scald resistance, and are readily useable for marker-assisted barley breeding. The new maps are available on-line at www.genica.net.au.
\end{abstract}

Additional keywords: microsatellite, Hordeum vulgare, genetic mapping, marker-assisted selection.

\section{Introduction}

Barley (Hordeum vulgare L.) is the world's fourth major cereal crop, and is an important export crop for Australia. Many molecular genetic linkage maps of barley have been created, first based on RFLP markers (Graner et al. 1991; Heun et al. 1991) and latterly on PCR-based markers (Ramsay et al. 2000). Adapted and improved barley varieties are now being released more rapidly than before through the use of marker assisted selection (MAS), with more than 27 loci being tracked with molecular markers in Australian barley breeding programs (Langridge and Barr 2003). MAS has 2 critical requirements: knowledge of the genetic loci controlling critical traits; and the availability of informative, inexpensive molecular markers linked to these loci. Simple sequence repeat (SSR) markers have become the most commonly used tool for MAS in barley breeding programs, and also the community standard marker system for genetic mapping studies. New SSR markers are developed by groups within the international cereal research community to enhance gene discovery and MAS programs. These markers require screening in barley germplasm to verify their location and accurately determine their linkage with key traits. Markers used in this project have been primarily developed through the increasingly used method of database mining of expressed sequence tag (EST) sequences in search of SSRs (Thiel et al. 2003; R. K. Varshney, unpublished). Compared with genomic SSR (gSSR) markers (Ramsay et al. 2000; Li et al. 2003), development of EST-derived SSR (eSSR) markers is very cost effective and in addition, eSSR markers possess a higher level of transferability for use across species (Varshney et al. 2005).

Over the past decade, genetic mapping has been used to identify many agronomic, quality, and disease resistance loci in Australian barley varieties (Langridge and Barr 2003). Accurate localisation of genes is dependent on having a high-quality genetic map with evenly spaced molecular markers at an appropriate density (Varshney et al. 2004). If these markers are also useable in marker-assisted breeding programs, the transfer of the technology and consequent genetic gains will be more rapidly achieved. 
This paper describes improvement of the quality and accuracy of 4 barley genetic maps through incorporation of new eSSR and gSSR markers as an aid to MAS and the future characterisation, mapping, and validation of marker trait associations for key traits that are as yet poorly or incompletely understood.

\section{Methods}

\section{Plant materials}

Four Australian barley populations with existing genetic maps were chosen for this study (Barr et al. 2003a, 2003b; Karakousis et al. 2003a, 2003b). These maps were developed from 3 doubled haploid (DH) populations: Galleon*Haruna Nijo (479 markers), Chebec*Harrington (372 markers), and Clipper*Sahara (285 markers), and $1 \mathrm{DH} /$ recombinant inbred line (RIL) population, Sloop*Alexis (312 markers).

\section{SSR genotyping and analysis}

In total, 216 primer pairs for eSSR markers (Thiel et al. 2003; R. K. Varshney, unpublished data) and 25 primer pairs for gSSR markers (Li et al. 2003) were used in the present study. Nineteen EST-derived SSR and indel markers were used (Rostoks et al. 2006). Standard PCR conditions and subsequent electrophoresis of amplified fragments were used (Karakousis et al. 2003c). All markers were tested for polymorphism on 8 parental lines. Subsequent genotyping of each DH or RI line was achieved by visually scoring each marker in accordance with the corresponding parental alleles.

\section{Comparative marker discovery}

A comparative approach to exploit the synteny between grass genomes was used to develop eSSRs linked to traits of interest. The primers of 2 eSSRs (gbm 1174 and gbm 1006) that flanked the Rpt4 gene (Williams et al. 1999) on chromosome $7 \mathrm{H}$ were used to identify the EST sequences from which they were derived (HU02H07 and bags37j12, respectively), which were aligned against the rice genome to identify rice chromosome 6 BAC clones AP005395 (89\% identity, e-value $\left.6^{\mathrm{e}-89}\right)$ and AP003634 (83\% identity, e-value $\left.6^{\mathrm{e}-21}\right)$. The rice BACs AP005445, AP003621, and AP004324, which were flanked by AP005395 and AP003634, were then used to search the barley EST collection. The 50 most significant barley ESTs for each search were then selected and searched for SSR motifs using a search tool at: http://hornbill.cspp.latrobe.edu.au/cgi-binpub/brassica/indexssr.pl. One SSR was selected from each set of barley ESTs that were derived from the rice clones except for the set from AP005445 in which 2 SSRs were selected. The primers and their sequences are as follows.

\section{AP005395-1F: ATGAACCGAACCTCTACTAC AP005395-1R: GCAACTTAGCATCACACACA}

AP005445-2F: ATTCCAACATCAATACAAGGA AP005445-2R: AGGGCGACATCAGCAAGT

AP003621-1F: GCTGGTCGCTCGTAAAGG AP003621-1R: TGTATGTATGTGTCGTCGTTG recombination fractions between all pairs of markers, regardless of the assignment of markers to chromosomes. These were compared with the recombination fractions produced using Map Manager and subsequent differences between marker pairs were evaluated to discover the best position for each marker. These improved maps formed the basis of this study.

\section{Addition of markers to maps}

The original maps were imported into Map Manager QTX (version QTXb20; Manly et al. 2001), using the Kosambi mapping function (Kosambi 1944; Lander et al. 1987), with threshold values of $P=0.05-0.001$. New genotypic data from the DH and RI populations were integrated into each chromosome using the 'Links report' function, then in conjunction with the 'Ripple' function and published maps to retain the established alignment and order, the marker was positioned. The number of double recombinants was evaluated and data were rechecked if necessary. Maps were drawn using MapChart (Voorrips 2002).

\section{Results}

The mapping populations Clipper*Sahara $(\mathrm{C} * \mathrm{~S})$, Chebec*Harrington $\left(\mathrm{C}^{*} \mathrm{H}\right)$, Galleon*Haruna Nijo $\left(\mathrm{G}^{*} \mathrm{H}\right)$, and Sloop*Alexis $\left(\mathrm{S}^{*} \mathrm{~A}\right)$ were obtained and screened for polymorphism with all of the 241 SSR markers. eSSR markers had a polymorphism rate of $40 \%$, compared with $60 \%$ polymorphism for gSSR markers. In total, 81 polymorphic markers were mapped on these populations, with coverage on all chromosomes; however, $6 \mathrm{H}$ was the least represented with only 2 new markers mapping to that chromosome (Fig. 1). These markers were previously unmapped in Australian germplasm, but chromosomal locations for some of the markers were known (Li et al. 2003; Thiel et al. 2003). From this study, the location of 56 previously unmapped eSSRs was determined and, in addition, 25 eSSR and gSSR markers were added to Australian maps for the first time. The new maps are available on-line at www.genica.net.au. The comparative marker discovery approach yielded 6 potential new SSRs, but only 2 (AP005395-1 and AP003621-1) out of the 6 eSSRs gave a clear polymorphism in a mapping population and were mapped to chromosome $7 \mathrm{H}$, near the target gene Rpt4.

\section{AP005445-1R: TGTATGTATGTGTCGTCGTTG AP005445-1F: GCTGGTCGCTCGTAAAGG}

AP004324-1F: AAATCAGTTGCCATCCGT AP004324-1R: CTGCTGTTGCTGTTGCTG

AP003634-1F: CCTCCTCTCACACCCTCTAC AP003634-1R: ATCACACGACACACCACAC

The overall length of the maps was compared before and after curation and addition of extra markers (Table 1). Even with the addition of extra markers, the overall map lengths

decreased substantially in 3 of the 4 maps. In particular, the
Curation of original maps

The original maps (Barr et al. 2003a, 2003b; Karakousis et al. $2003 a, 2003 b$ ) were evaluated to establish a firm foundation of quality control and data curation using the approach of Lehmensiek et al. (2005). The procedure involved applying computer code using S-Plus (Insightful Corp.) to the genotypic data, which calculates the 


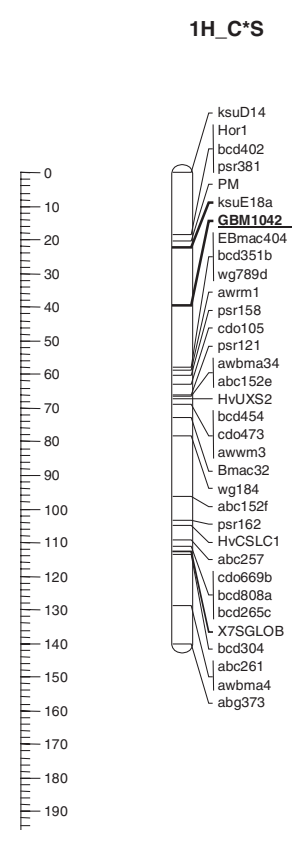

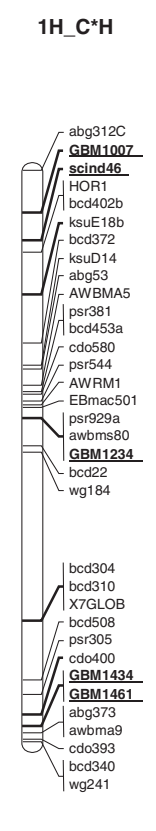

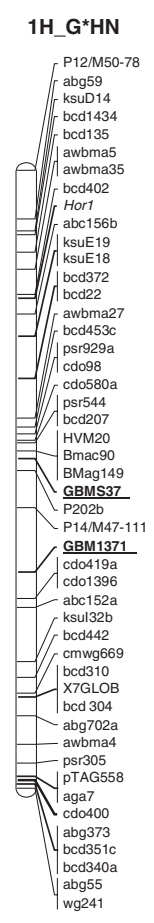

2H_G*HN

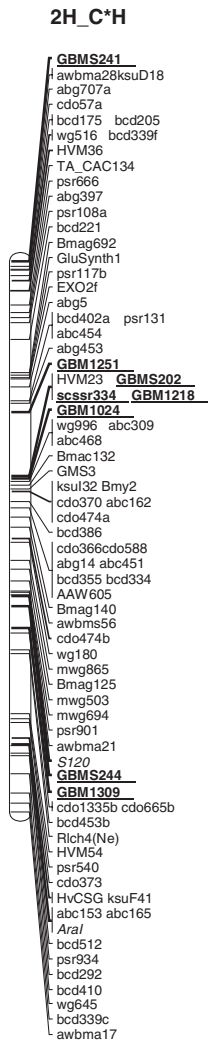

1H_S*A

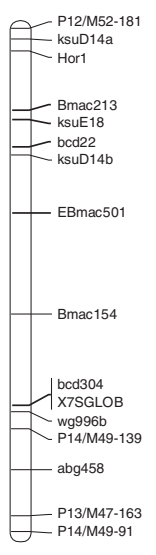

2H_S*AI

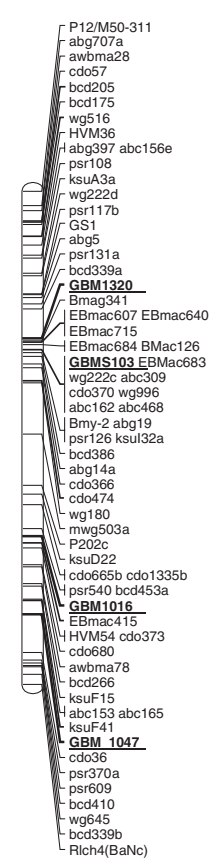

Fig. 1. Updated chromosomes $1 \mathrm{H}-7 \mathrm{H}$ of Australian mapping populations: Clipper*Sahara $(\mathrm{C} * \mathrm{~S})$, Chebec*Harrington $(\mathrm{C} * \mathrm{H})$, Galleon*Haruna Nijo $\left(G^{*} H N\right)$, Sloop*Alexis $\left(S^{*} A\right)$. New SSR markers are bold and underlined. Scale bar indicates centimorgan distances. 


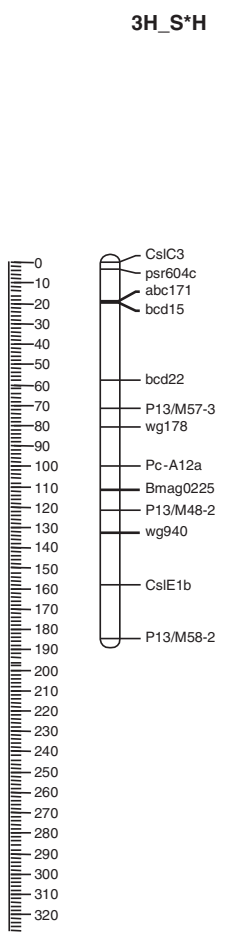

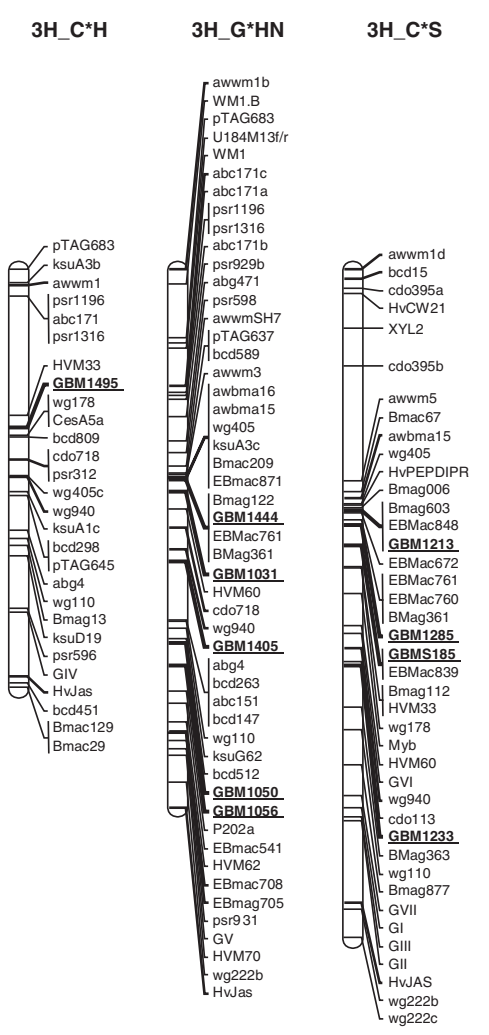

$5 \mathrm{H} \mathrm{S}^{*} \mathrm{Al}$

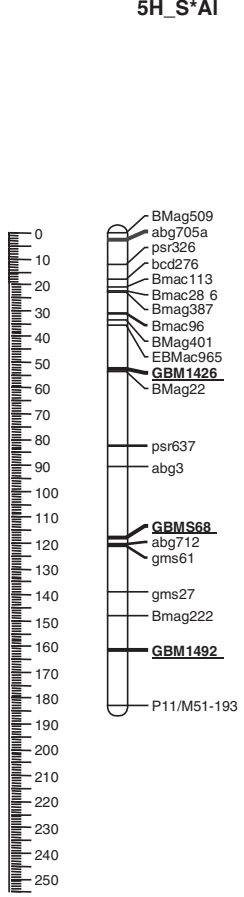

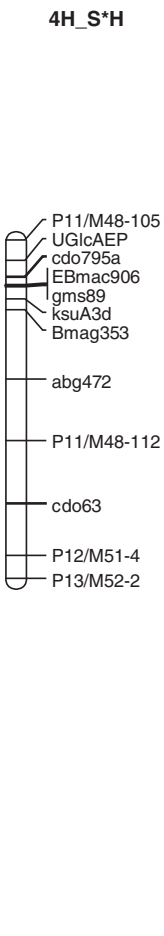

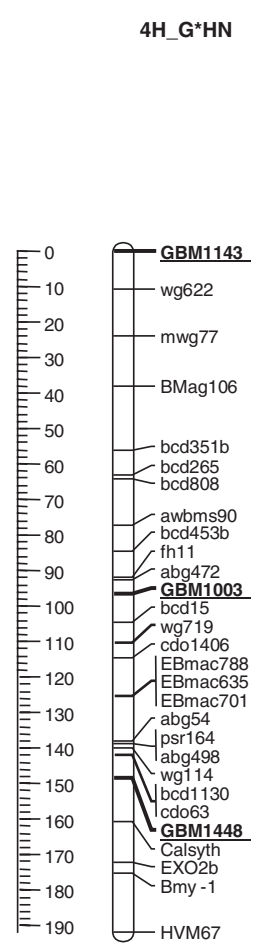

4H_C*H
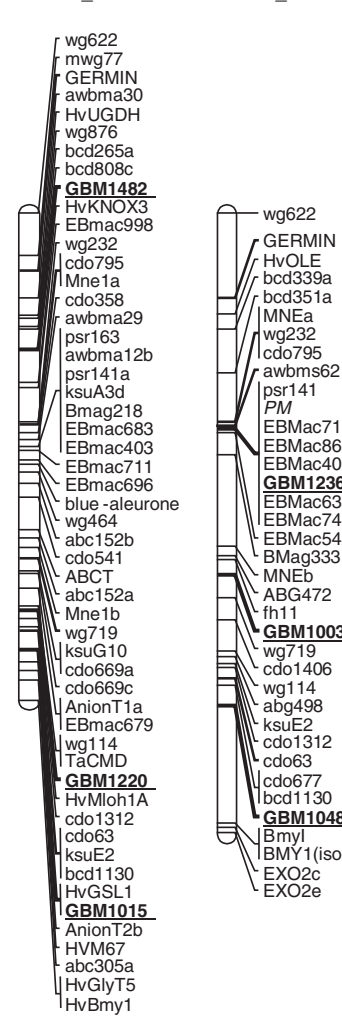

- MNEa

llog232

Psr141

EBMac71

EBMac863 GBM1236 EBMac749 EBMac542

- 1 MNEb 333

ABG472

GBM1003

$\left\{\begin{array}{l}\text { wg719 } \\ \text { cdo1406 }\end{array}\right.$

- $-w_{\text {wg114 }}$

ksuE2

cdo1312

cdo63

bcd1130

9 YBmyl EXO2C
EXO2e

$5 \mathrm{HCxS}$
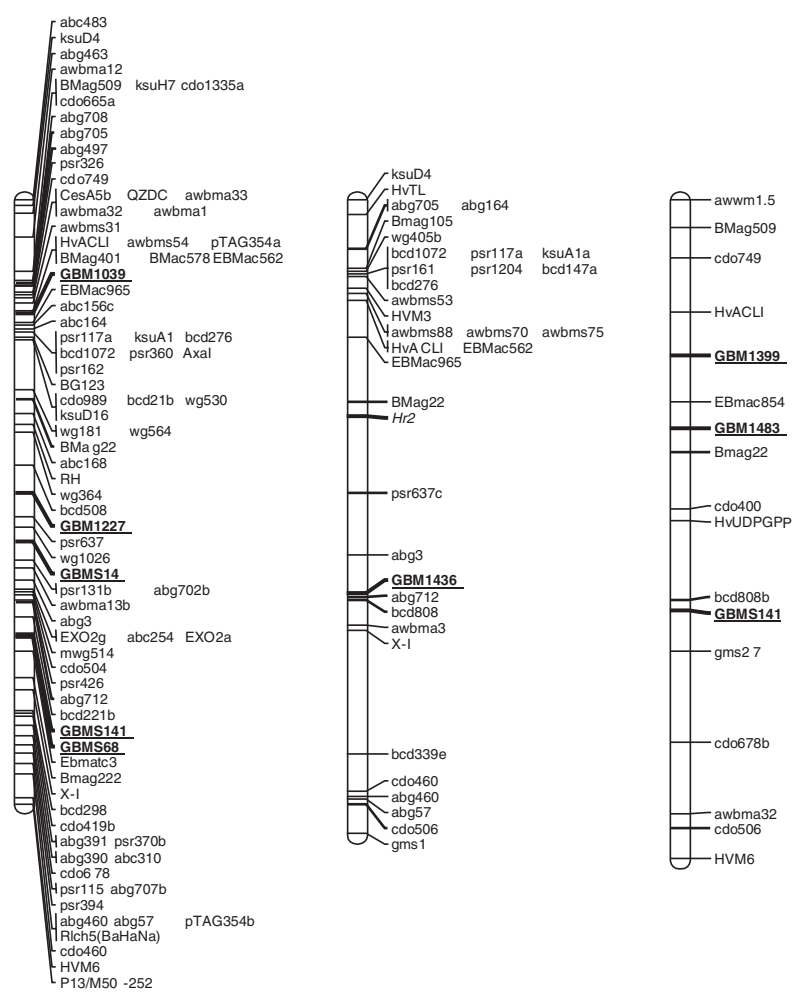

Fig. 1. (continued) 

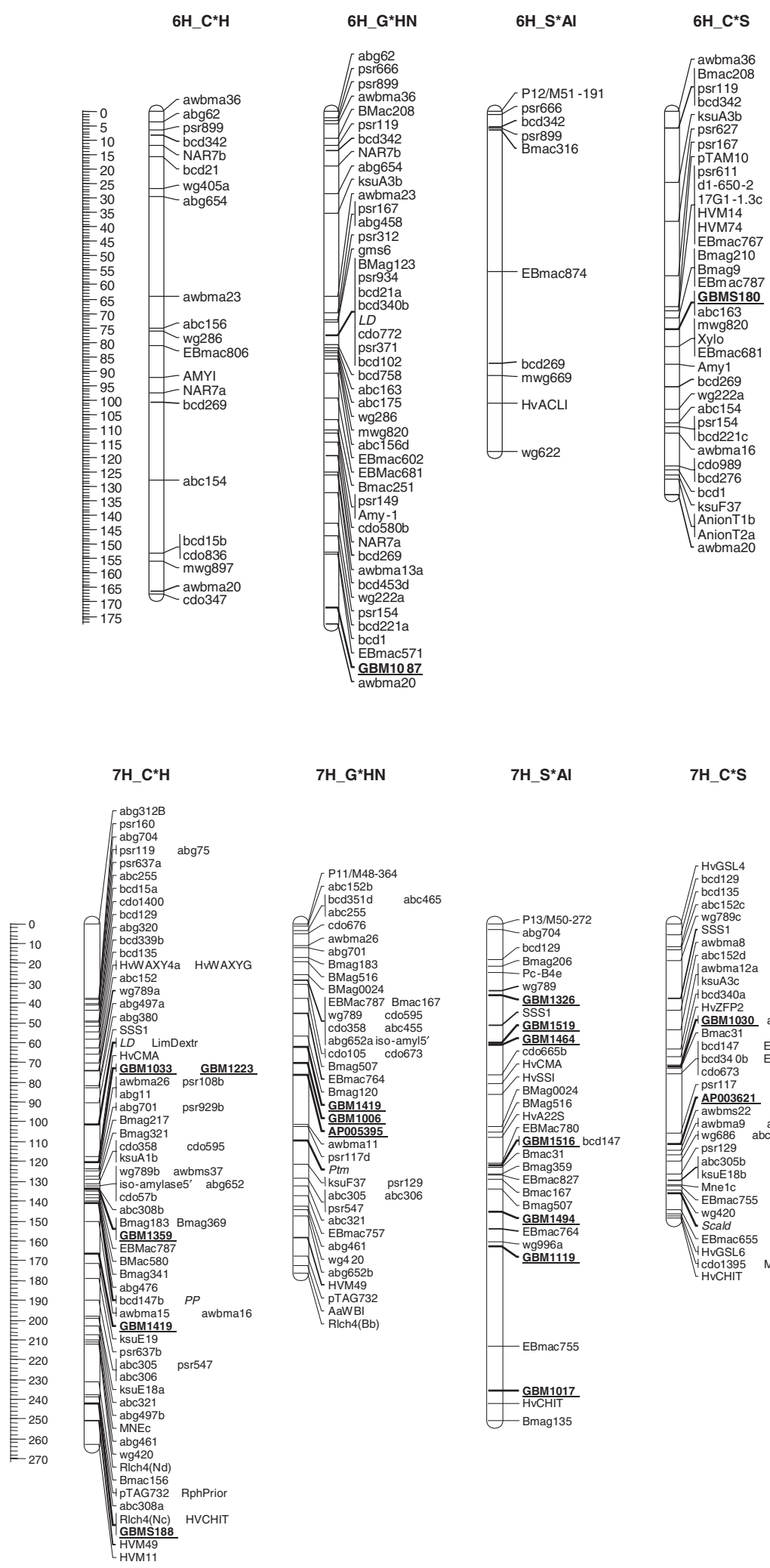

7H_G*HN

7H_S*AI

7H_C*S
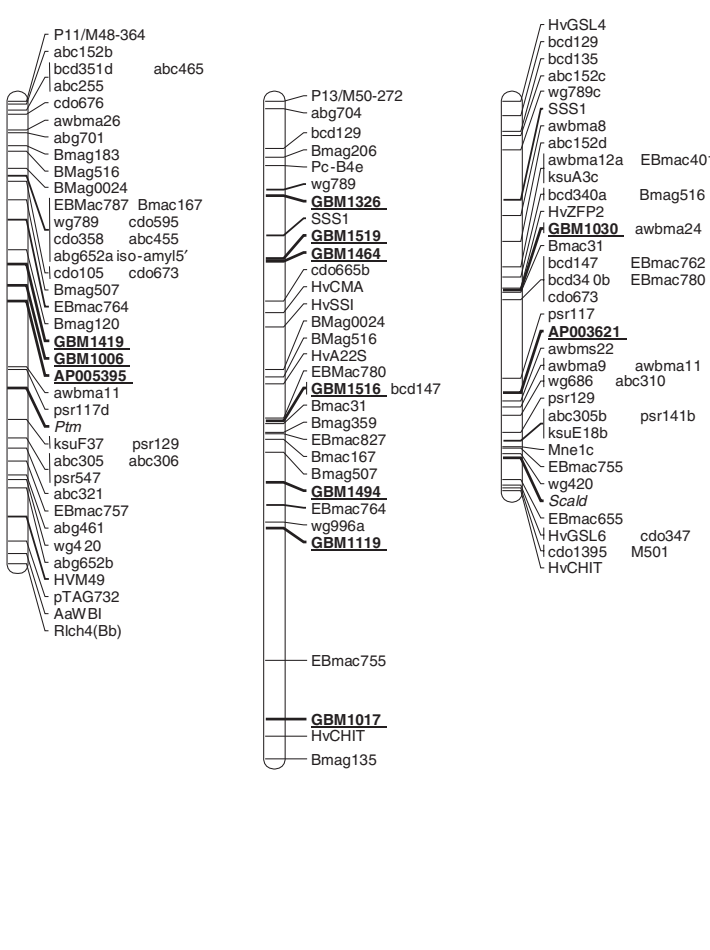

Fig. 1. (continued) 
Table 1. Total genome length (cM) for each Australian barley mapping population before and after addition of new markers

\begin{tabular}{lcccc}
\hline & Chebec*Harrington & Galleon*Haruna Nijo & Clipper*Sahara & Alexis*Sloop \\
\hline $\begin{array}{l}\text { Before curation and addition } \\
\text { of new markers }\end{array}$ & 1618.4 & 1570.5 & 1816.2 & 1241.2 \\
$\begin{array}{l}\text { After curation and addition } \\
\text { of new markers }\end{array}$ & 1214.5 & 1452.8 & 950.9 & 1247.0 \\
Number of new markers added & 23 & 22 & 16 & 27 \\
\hline
\end{tabular}

length of the Clipper*Sahara map decreased by over $800 \mathrm{cM}$, highlighting the benefits of the curation process.

\section{Discussion}

The addition of these new SSR markers to genetic maps of barley serves dual purposes: improving chromosome coverage and marker density, and replacing expensive and complex marker technologies with readily implementable, inexpensive and robust SSR technology. This provides barley breeders with a greater number of potentially useable markers to use for tracking a locus, overcoming the low levels of marker polymorphism between parents in breeding programs, which is still the greatest impediment to MAS (Varshney et al. 2004). Greater coverage of the distal ends of chromosome maps with SSRs has been achieved with the new markers, and this is very helpful in terms of marker order and map alignment.

Marker order has been established using a combination of techniques, aiming to minimise chromosome length and the number of double recombinants whilst maximising LOD scores. In addition, the approximate location and order of markers has been checked using a comparative map viewer (www.genica.net.au), although a greater emphasis has been placed on maintaining high LOD scores with the least number of crossovers between adjacent markers. Even though it is possible to continue to increase marker density further, researchers and breeders will determine when these maps have obtained a degree of saturation suitable for effective MAS, gene exploration, and quantitative trait loci detection.

Random marker screening to improve barley maps rarely finds new markers linked to important loci. Markers were selected from the set of gSSR markers (Li et al. 2003) as having potential links to important genes and were mapped in those locations accordingly. The eSSR markers (Varsheny et al., unpublished) also mapped to regions of interest; however, the random development of the markers from EST databases can result in the positioning of markers to chromosome locations with no known genes. However, bioinformatics-based marker discovery, based on synteny between triticeae species, may be the most effective method to produce highly informative and locusspecific SSR markers. This approach was used in this study to tag the Rpt4 gene (Williams et al. 1999) on chromosome 7H with 2 new eSSR markers, and many extra in-silico-derived eSSR markers are also available to fine-map this gene.

The polymorphism rate for EST-derived SSR markers was $44 \%$ relative to $60 \%$ for markers identified from genomic libraries. Karakousis et al. (2003c) found that SSRs derived from random genomic sequences were twice as polymorphic in Australian germplasm as those derived from ESTs, and Pillen et al. (2000) generated low PIC values for ESTderived SSR markers when screened against European and North American barley cultivars. However, the inexpensive discovery of potentially large numbers of genetically or functionally targetted SSRs via ESTs may outweigh their lower informativeness.

Currently, these barley genetic maps provide important marker-trait associations to breeding programs for disease resistance and tolerance genes, quality traits for malting, and agronomic traits for improved yield potential, frost tolerance, and maturity. Several of the new SSR markers mapped in this study are linked to genes for resistance to diseases such as cereal cyst nematode, net blotch, and scald and are ready for immediate implementation, as well as for use in future mapping studies.

\section{References}

Barr AR, Jefferies SP, Broughton S, Chalmers KJ, Kretschmer JM, Boyd WJR, Collins HM, Roumeliotis S, Logue SJ, Coventry SJ, Moody DB, Read BJ, Poulsen D, Lance RCM, Platz GJ, Park RF, Panozzo JF, Karakousis A, Lim P, Verbyla AP, Eckermann PJ (2003b) Mapping and QTL analysis of the barley population Alexis $\times$ Sloop. Australian Journal of Agricultural Research 54, 1117-1123. doi: 10.1071/AR02190

Barr AR, Karakousis A, Lance RCM, Logue SJ, Manning S, Chalmers KJ, Kretschmer JM, Boyd WJR, Collins HM, Roumeliotis S, Coventry SJ, Moody DB, Read BJ, Poulsen D, Li CD, Platz GJ, Inkerman PA, Panozzo JF, Cullis BR, Smith AB, Lim P, Langridge P (2003a) Mapping and QTL analysis of the barley population Chebec $\times$ Harrington. Australian Journal of Agricultural Research 54, 1125-1130. doi: 10.1071/AR02215

Graner A, Jahoor A, Schondelmaier J, Siedler H, Pillen K, Fischbeck G, Wenzel G, Herrmann RG (1991) Construction of an RFLP map of barley. Theoretical and Applied Genetics 83, 250-256. doi: 10.1007/BF00226259

Heun M, Kennedy AE, Anderson JA, Lapitan NLV, Sorrells ME, Tanksley SD (1991) Construction of a restriction fragment length polymorphism map for barley (Hordeum vulgare). Genome 34, 437-447. 
Karakousis A, Barr AR, Kretschmer JM, Manning S, Jefferies SP, Chalmers KJ, Islam AKM, Langridge P (2003b) Mapping and QTL analysis of the barley population Clipper $\times$ Sahara. Australian Journal of Agricultural Research 54, 1137-1140. doi: 10.1071/AR02180

Karakousis A, Barr AR, Kretschmer JM, Manning S, Logue SJ, Roumeliotis S, Collins HM, Chalmers KJ, Li CD, Lance RCM, Langridge P (2003a) Mapping and QTL analysis of the barley population Galleon $\times$ Haruna Nijo. Australian Journal of Agricultural Research 54, 1131-1136. doi: 10.1071/AR02179

Karakousis A, Gustafson JP, Chalmers KJ, Barr AR, Langridge P (2003c) A consensus map of barley integrating SSR, RFLP, and AFLP markers. Australian Journal of Agricultural Research 54, 1173-1185. doi: 10.1071/AR02177

Kosambi DD (1944) The estimation of map distances from recombination values. Annals of Eugenics 12, 172-175.

Lander ES, Green P, Abrahamson J, Barlow A, Daly MJ, Lincoln SE, Newburg L (1987) MAPMAKER, an interactive computer package for constructing primary genetic maps of experimental and natural populations. Genomics 1, 174-181. doi: 10.1016/08887543(87)90010-3

Langridge P, Barr A (2003) Preface. Australian Journal of Agricultural Research 54, i-iv. doi: 10.1071/ARv54n12_PR

Lehmensiek A, Eckermann PJ, Verbyla AP, Appels R, Sutherland MW, Daggard GE (2005) Curation of wheat maps to improve map accuracy and QTL detection. Australian Journal of Agricultural Research 56, 1347-1354.

Li JZ, Sjakste TG, Roder MS, Ganal MW (2003) Development and genetic mapping of 127 new microsatellite markers in barley. Theoretical and Applied Genetics 107, 1021-1027. doi: 10.1007/s00122-003-1345-6

Manly KF, Cudmore RH Jr, Meer JM (2001) Map Manager QTX, crossplatform software for genetic mapping. Mammalian Genome 12, 930-932 . doi: 10.1007/s00335-001-1016-3

Pillen K, Binder A, Kreuzkam B, Ramsey L, Waugh R, Forster J, Leon J (2000) Mapping new EMBL-derived barley microsatellites and their use in differentiating German barley cultivars. Theoretical and Applied Genetics 101, 652-660. doi: 10.1007/s001220051527
Ramsay L, Macaulay M, degli Ivanissevich S, Maclean K, Cardle L, Fuller J, Edwards KJ, Tuvesson S, Morgante M, Massari A, Maestri E, Marmiroli N, Sjakste T, Ganal M, Powell W, Waugh R (2000) A simple sequence repeat-based linkage map of barley. Genetics 156, 1997-2005.

Rostoks N, Mudie S, Cardle L, Russell J, Ramsay L, Svensson JT, Wanamaker S, Walia H, Rodriguez E, Hedley PE, Liu H, Close TJ, Marshall DF, Waugh R (2006) Single nucleotide polymorphism discovery in barley facilitates development of an integrated linkage map and identifies regions of conserved gene order in barley and rice. Molecular Genetics and Genomics, (In press).

Thiel T, Michalek W, Varsheny RK, Graner A (2003) Exploiting EST databases for the development and characterization of genederived SSR-markers in barley (Hordeum vulgare L). Theoretical and Applied Genetics 106, 411-422.

Varshney RK, Graner A, Sorrells ME (2005) Genic microsatellite markers, their characteristics, development and application to plant breeding and genetics. Trends in Biotechnology 23, 48-55. doi: 10.1016/j.tibtech.2004.11.005

Varshney RK, Prasad M, Graner A (2004) Molecular marker maps of barley, a resource for intra- and interspecific genomics. In 'Molecular markers in improvement of agriculture and forestry'. (Eds G Wenzel, L Horst) pp. 229-243. (Springer Verlag: Germany)

Voorrips RE (2002) MapChart, Software for the graphical presentation of linkage maps and QTLs. Journal of Heredity 93, 77-78. doi: $10.1093 /$ jhered/93.1.77

Williams KJ, Lichon A, Gianquitto P, Kretschmer JM, Karakousis A, Manning S, Langridge P, Wallwork H (1999) Identification and mapping of a gene conferring resistance to the spot form of net blotch (Pyrenophera teres f. maculata) in barley. Theoretical and Applied Genetics 99, 323-327. doi: 10.1007/s001220051239

Manuscript received 8 November 2005, accepted 13 April 2006 